Article

\title{
Perceptions and Consumption of Bottled Water at the University of the Basque Country: Showcasing Tap Water as the Real Alternative towards a Water-Sustainable University
}

\author{
José Ramón Díez $^{1}$ (D), Iñaki Antigüedad ${ }^{2}$, Elena Agirre ${ }^{1,3}$ and Arantza Rico 1,3,*(D) \\ 1 Department of Mathematics and Experimental Sciences Education, Faculty of Education of Bilbao, \\ University of the Basque Country (UPV/EHU), Campus Sarriena s/n, 48940 Leioa, Spain; \\ joseramon.diez@ehu.eus (J.R.D.); elena.agirre@ehu.eus (E.A.) \\ 2 Department of Geodynamics, Faculty of Science and Technology, University of the Basque \\ Country (UPV/EHU), Campus Sarriena s/n, 48940 Leioa, Spain; inaki.antiguedad@ehu.eus \\ 3 Department of Mathematics and Experimental Sciences Education, Faculty of Education and Sport, \\ Araba Campus, Juan Ibañez de Sto Domingo, 01006 Vitoria-Gasteiz, Spain \\ * Correspondence: arantza.rico@ehu.eus; Tel.: +34-945-01-4188
}

Received: 7 August 2018; Accepted: 23 September 2018; Published: 26 September 2018

\begin{abstract}
This paper examines the beliefs and environmental attitudes of university individuals towards bottled and tap water use and examines tap and bottled water availability and sales volumes at the University of the Basque Country. The research employed a mixed methods approach including (i) an exploratory survey to document environmental beliefs and behaviors towards bottled and tap water; (ii) written questionnaires addressed to faculty administrators to inquire about accessibility to tap water and, (iii) personal interviews with restaurant managers to inquire about sales volumes of bottled water. Respondents to our survey predominately drink tap water and no health or taste issues associated with its consumption are perceived among respondents reporting to drink two or fewer bottles per week. These results imply that in our context, there are positive perceptions towards tap water and pro-environmental behavior regarding water consumption. However, respondents also claimed to use reused plastic water bottles as the most common tap water container. Moreover, there was widespread presence of bottled water sales at university premises, confirming the ubiquity of this commodity worldwide. Collectively, both survey and sales volume analyses suggest that a greater shift in sustainable behavior is needed in our community. Regarding measures and policies to promote tap water accessibility, considerable differences were found within and between campuses. These findings should help to inform university managers and support sustainability goals where bottled water consumption could be minimized or even eliminated.
\end{abstract}

Keywords: bottled water; tap water; consumer perceptions; environmental attitudes; university community

\section{Introduction}

An increasing number of universities worldwide are adopting sustainability approaches to manage their facilities and holistic approaches that explicitly link research, educational, operational, and outreach activities [1,2], because the environmental issues that must be tackled in public institutions are complex and multifaceted [3]. Moreover, there is little doubt that to achieve a high quality of life, protecting the environment and maintaining natural resources are key elements of sustainable university management [4]. The University of the Basque Country (Spanish: Universidad del País 
Vasco, UPV; Basque: Euskal Herriko Unibertsitatea, EHU; UPV/EHU) in the North of Spain is a 40-year-old institution with 45,000 students, 5000 academic staff, and three main campuses located in each province of the Basque Autonomous Region. As stated in its Statutes, the UPV/EHU is committed to exercise its daily activities in a sustainable way, economically, socially, and environmentally [5], which is also defined in its Strategic Planning 2018-2021 [6]. Therefore, at college or department levels, campus initiatives that contribute to sustainability management and education are encouraged and financially promoted.

Despite being one of the most straightforward practices along with reducing fossil fuel emissions and waste management, consumption of bottled water continues to be a pressing issue in this and other Spanish universities. In this sense, single-use plastic bottled water is available in nearly all facilities at UPV /EHU, and it is an example of how available this commodity is in our society. In fact, the consumption of bottled water continues to increase. After a $20 \%$ decrease during the last financial crisis, the Spanish consumption per capita in 2016 went up to $121 \mathrm{~L}$, making Spain the 6th largest consumer in the European ranking and among the seven countries whose consumption is above the EU average [7].

\section{Literature Review}

There is little doubt that bottled water consumption has a clear cumulative impact on the environment, from the accumulation of plastic in landfills and oceans to the pollution generated during its production and distribution [8-10]. In recent years, the transfer of chemicals, such as Bisphenol A or antimony, from the plastic to the water has become another matter of concern [11,12]. In contrast, there is overwhelming evidence to support tap water consumption, due to its energy efficiency, its contribution to reduce plastic litter and greenhouse gas emissions, and to its positive impact on climate change mitigation and the environment as a whole $[8,13]$. This has been highlighted recently in Europe by the European Citizens' Initiative called "Water is a Human Right", that has campaigned for a revision of the drinking water directive [13]. One of the main arguments to showcase the benefits of municipal tap water in Europe is that due to its high regulation, health and safety benefits over bottled water are well substantiated [14].

Outside Europe and at the municipal scale, the environmental impact of plastic bottles has led in some cases to the ban of bottled water commercialization in public spheres. Pioneering examples are found at the city of Bundanoon in Australia, which banned the sales of bottled water in its city in 2009 [15] and, more recently, the city of San Francisco (USA) banned the sale of single-use bottled water on city properties [16], followed by Hong Kong and Montreal [17,18]. With regards to North American higher education institutions, both banning of bottled water sales and increasing access and availability to tap water has been on agendas through campaigns such as "Ban the Bottle", which advocates bans on one-time-use plastic water bottles in many colleges/universities and public organizations $[19,20]$.

In the European context, in May 2018, the European Commission proposed new EU-wide rules to target the 10 single-use plastic products present in our oceans [21]. If the proposal is successful, it will be required that member states collect $90 \%$ of single-use plastic drink bottles by 2025 , so large-scale bans of single use plastic bottles are not envisioned yet. In our local context, to our knowledge, no ban of single use plastic bottle has been implemented in Spanish universities.

Without a ban, consumers' perceptions play a huge role in bottled water consumption [22-24]. This has been demonstrated in other studies aimed at university students, showing that when it comes to reducing consumption, important differences exist in beliefs between high and low users of bottled water $[10,24,25]$. This is a challenging scenario because, even in countries where clean, potable tap water is available at very low or no cost [26], consumers resist government environmental and health claims in favor of tap water [27]. This can be reinforced when there is distrust of the government, and by the information portrayed in the media and marketing strategies. In consequence, all these factors become influential for the consumption of bottled water instead of tap water [28,29]. As mentioned earlier, some studies argue that to elicit effective behavioral change, attitudes and beliefs and the 
factors that modulate them have to be taken into account. For example, personal norms represented by the self-impact (feeling guilty when drinking bottled water) and the intention to impact others (persuading others to drink less bottled water) do have a significant effect on the drinking water behavior [24,25]. In this sense, van der Linden [10], argued that combining the activation of social norms with the provision of persuasive information elicited the greatest reduction in intentions to purchase bottled water.

The recent move towards sustainability education led by many universities implies that these institutions play an active role in providing students and academic and clerical staff with a broad understanding of sustainability issues, both environmental and social [30]. Targeting the university community can help to understand the perceptions and choices towards drinking water and reduce bottled water consumption at the university but it can also serve as a catalyst to promote practical change in a wider sphere towards a more sustainable future [20,25,31,32].

While there is a growing body of studies addressing consumers' perception towards tap water and bottled water use in universities [10,24,25], there is still a need to identify these attitudes in our context, where commercialization, availability, and consumption of bottled water has increased above the European average [7]. Our research aims to:

1. Examine through an exploratory survey the university community's environmental perception towards bottled and tap water based on Saylor et al.'s [22] questionnaire.

2. Examine tap and bottled water availability in university premises.

3. Examine bottled water sales in the university's main restaurants.

Our hypothesis is that respondents' environmental perceptions will differ based on the individual's declared bottled water consumption, as it has been shown previously elsewhere [10,24,25]. We also hypothesize that participants' beliefs may not be homogeneous across age group or the collective (student, academic staff, or clerical staff) to which they belong.

Results show that respondents to our survey predominately drink tap water and health risks or taste issues associated with its consumption are not perceived, but these views are mostly among those that buy few bottles per week. Regarding university collectives, academic staff have the lowest bottled water consumption compared to students or clerical staff. Bottled water availability and sales volume and the observed differences across centers with regards to tap water availability, shows that management strategies lag behind peoples' environmental attitudes. The implications for university managers in light of these and other results are further discussed and managerial strategies are proposed.

\section{Materials and Methods}

\subsection{Exploratory Survey about Bottled and Tap Water Use}

\subsubsection{Sampling Procedure}

A questionnaire addressing the perceptions about bottled and tap water and the use of reusable non-plastic bottles was conducted with a random sample of students and faculty and administrative staff. The aim was to gain insights on their behaviors and perceptions regarding drinking water and its environmental impact. The prospective sample consists of more than 50,000 people from UPV /EHU, where 41,700 are undergraduate students, 2180 are master students, around 2500 are pre-doctoral students, 5200 are lecturers and research staff, and around 1800 are administrative staff. These are unequally distributed within the main three campuses, as well as in other smaller facilities. Most of these people stay 6 to $8 \mathrm{~h}$ on average in one of the university campuses. The questionnaire was registered in the on-line survey website "encuestafacil.com" (Encuesta Fácil S.L., Madrid, Spain) and advertised in the university e-mail distribution lists. 


\subsubsection{Questionnaire Design}

We performed an exploratory survey regarding water consumption during May and June 2012 based on a previous study [22]. The survey was translated from English to both Spanish and Basque, published in "encuestafacil.com", and advertised in the university distribution lists and locally by selected lecturers in classrooms located in the 3 different campuses. The statistics software $R$ and its graphical user interface $\mathrm{R}$ commander [33] were used to perform a quality assessment of the translated survey using the following statistics: (i) the discriminating power of our preliminary survey using small and moderate effect sizes (Cohen's $d=0.2,0.5$; (ii) the difficulty index for numerical variables; (iii) the attraction index or frequency analysis for factor variables, and (iv) the homogeneity index or Cronbach's alpha. The items that did not comply with our quality standards were reformulated. In some cases, the item addressed an issue that may not be relevant in our local context, and was removed from the questionnaire (for example, drinking filtered tap water versus unfiltered tap water).

The final questionnaire was created in Spanish and Basque and published in the same on-line site on February 2013 and advertised for four months. The survey included 18 items grouped in three main categories that assessed: (i) perceptions about bottled water versus tap water use regarding safety, taste, tap water availability, and convenience of reusing plastic bottles; (ii) perceptions about reusable non-plastic bottles regarding safety, convenience, and environmental awareness, and (iii) perceptions about tap water use regarding price, safety, convenience, and environmental awareness.

The questionnaire also included items inquiring about demographic characteristics, such as gender, age, and university collective and a question that allowed organizing the responses in groups of weekly bottled water consumption (see Section 3.1.3). The original survey in Spanish and Basque is available in Supplementary File 1. Since one of the goals of this work was to examine whether the level of bottled water consumption had a role in people's perceptions about bottled and tap water use, an ordinal variable was created, which allowed us to perform subsequent statistical comparisons.

\subsubsection{Survey Data Analysis}

Survey responses were downloaded from "encuestafacil.com" as a text file that was exported to $\mathrm{R}$ Commander statistical software. Based on the distribution of responses to the question "During a single week, how many single-serving bottles of water did you drink?", we created an ordinal variable for the level of bottled water consumption. This variable categorized respondents into user groups based on how many single-serving bottles of water they reported drinking in the past week (i.e., a response of zero bottles was re-coded as 1, 1 or 2 bottles was re-coded as 2, 3 to 5 bottles was re-coded as 3, and 6 or more bottles was re-coded as 4 ). This ordinal variable facilitated comparisons between groups with different levels of bottled water consumption across other variables, including the benefits they perceived of drinking tap water as opposed to bottled water, or the benefits of using reusable non-plastic bottles. Statistical analysis included Pearson's Chi-square tests of bottled water usage by sex, gender, university population, or age. Perceptions of bottled and tap water use were also compared within different university populations (Lecturer/Researcher, Students, and Clerical or Administrative staff).

Since data were extracted from Likert items, they were treated as ordinal and analyzed using non-parametric methods including frequency distributions for general item response analysis. For multiple comparisons, a Kruskal-Wallis test by ranks or one-way ANOVA on ranks test [34] was employed to compare perceptions about bottled and tap water by bottled water user groups or university population. Consequently, mean rank values were calculated for each group of weekly bottled water consumption and are depicted in Tables 1-3. For ease of interpretation, mean rank values scoring low correspond to low levels of agreement and mean rank values scoring high correspond to high levels of agreement. Box-plots depicting median and other percentile values were produced for selected items, because they describe more accurately the central tendency of Likert data [35]. Post hoc pairwise comparisons of mean rank values were performed using "kluskalmc" from the package pgirmess [36] and are available in Supplementary File 2. 


\subsection{Survey Directed to University Schools' Deans and Administrators from Research Centers and Administration Buildings}

Another aim of this work was to evaluate the accessibility to tap water in each faculty or center of our university. Administrators and deans of different faculties or colleges, research centers, and administration buildings were contacted by e-mail at least three times and asked them to fill an on-line questionnaire of 7 dichotomous questions (YES/NO), which inquired about such accessibility in staff and student common rooms, dining halls, and canteens and about the use of tap water in academic ceremonies. The 7th question asked specifically whether any action to reduce plastic bottles had been carried out in their centers, and respondents were encouraged to justify their answers. The survey was sent to the university's 31 schools' deans and administrators, and to the administrators of 7 research centers and 3 administration premises and remained open from March to June 2014. In some cases and in order to cover the full sample, telephonic interviews were carried out. Frequencies of responses were calculated for the dichotomous questions and regarding the 7th question, a qualitative analysis was carried out to categorize the answers into different strategies at the faculty level to reduce bottled water consumption.

\subsection{Personal Interviews to Restaurant Managers}

When this research was carried out, the University of the Basque Country comprised 30 Faculties or Colleges, 21 of which also hold a restaurant. Whenever possible, an appointment was made with the restaurant manager in order to conduct a personal interview. If such a personal appointment was not possible, a telephonic interview was arranged. The interview aimed to measure: (i) the monthly sales volume of bottled water, whether a particular brand was chosen and if so, the criteria governing that choice, (ii) the recycling policy of plastic bottles, and (iii) whether free tap water was provided with meals. The sales volume of plastic water bottles from vending machines in university premises was not calculated except for the biggest canteen located in Leioa Campus, where a direct control of sold units was available.

\section{Results}

\subsection{Respondent Characteristics to the Exploratory Survey}

A total of 1677 questionnaires were completed. Since $15 \%$ of the respondents had missing values, full statistical analysis was performed with a total of 1435 questionnaires. A higher proportion of respondents were female $(61.2 \%)$ than male $(38.8 \%)$. Thus, women were more likely to respond to our survey than would be expected based on their proportion $(52.4 \%)$ at the University of the Basque Country. The distribution of responses was fairly balanced between students (37.7\% of responses), lecturer/researcher staff (35.3\%), and clerical staff (27\%), while their proportions at the university are $85.3 \%, 11 \%$, and $3.7 \%$, respectively. The survey could be answered either in Spanish or Basque and the distribution of responses in each language was $63 \%$ and $37 \%$, respectively.

\subsection{Use of Plastic Bottled Water and Tap Water at the UPV/EHU among Survey Participants}

Respondents were asked to specify how many single-use water bottles they had consumed in a week by choosing from 4 categories (1: 0 bottle, 2: 1 or 2 bottles, $3: 3$ to 5 bottles, and 4: more than 6 bottles). The majority of the respondents $(50.2 \%)$ reported that they did not use any plastic bottle during the past week, while approximately $33 \%$ of respondents reported drinking at least one or two bottles of water in the past week. Approximately $13 \%$ and $4 \%$ of the respondents reported to have consumed from 3 to 5 to more than 6 bottles, respectively, in the past week (Figure 1A). The respondents that chose the 1st or 2nd category were asked to specify the material in which they used to drink water. Approximately $52 \%$ stated that they used a reused plastic bottle, and $12 \%$ responded that they used a reused glass bottle (data not shown). Collectively, these results indicate that members of the UPV/EHU community more regularly drink tap water out of reused plastic water bottles than 
purchasing single-use plastic water bottles. Interestingly, a significant proportion of respondents drank water directly from the tap or using a glass (30\%, data not shown).

A

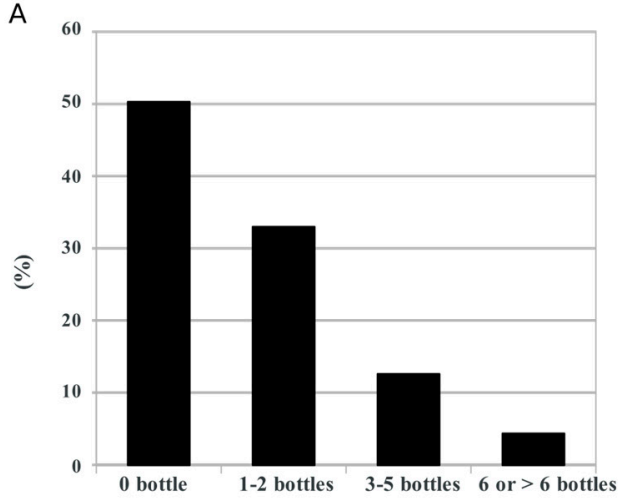

B

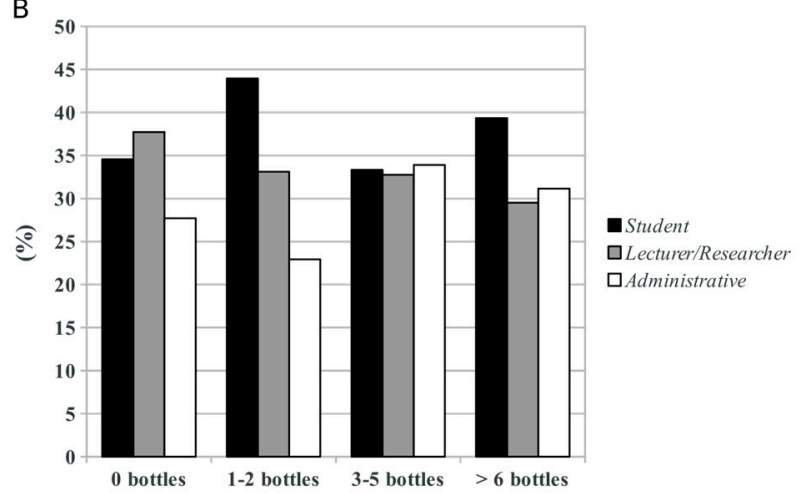

Figure 1. Self-reported weekly bottled water consumption at the University of the Basque Country UPV/EHU. Data were obtained in 2013. (A) Levels of weekly use are indicated in the $x$ axis. (B) Levels of bottled water consumption for each university group, which are shown in the legend. A Chi-square test for independence revealed that the variable level of bottled water consumption and university collective are not independent $\left(\chi^{2}=16.92, \mathrm{df}=6, p\right.$-value $\left.=0.009562\right)$.

Analysis of the survey results did not reveal a significant relationship between a respondent's gender and the amount of bottled water they reported drinking $\left(\chi^{2}=7.16, p\right.$-value $=0.07$; data not shown), although a higher proportion of men, (54.4\%) reported not drinking bottled water during the past week than women $(48.5 \%)$.

We also looked at whether there could be a relationship between the level of bottled water consumption and the university group to which the respondent belonged. A Chi-square test for independence revealed that the level of bottled water consumption differed among students, lecturer/researchers, and administrative staff $\left(\chi^{2}=16.92, p<0.05\right.$; Figure 1B). In fact, the majority of non-users of bottled water were lecturer/researchers (37.7\%), while for the 2nd and 4th category (1-2 bottles or more than 6 bottles per week), students yielded the highest proportions ( $43.9 \%$ and $39.3 \%$, respectively; Figure 1B). These results indicate that, if consumption is to be reduced through behavior change strategies $[10,25]$, students deserve particular attention.

\subsection{Environmental and Moral Perception about Bottled Water Use}

Participants were asked to respond to five questions following a 5-point Likert question regarding their perception about the safety and taste of bottled water versus tap water, and whether they perceived that refilling and reusing plastic bottles took too much effort. A fifth question aimed to identify self-impact (feeling guilty) with respect to discarding bottles after a single use. Figure 2 shows notched box plot diagrams across levels of consumption and Table 1 depicts the mean rank values calculated for each group of weekly bottled water consumption. Low consumers of bottled water (Groups 1 and 2) disagreed with claims about the lack of safety of tap water and the lack of facilities and inconvenience of refilling plastic bottles (Figure 2). The agreement with regards to a better taste of bottled versus tap water was higher in high consumers (Figure 2). Kruskal-Wallis rank comparisons in Table 1 confirms that respondents stating that they drank 3 or more bottles per week expressed more strongly their agreement regarding the better taste or safety of bottled water, and agreed more strongly about the inconvenience of refilling plastic bottles. This is in agreement with previous studies, which link bottled water consumption with organoleptic and health concerns $[10,24]$. In general, all respondents disagreed with the statement that reusing plastic bottles involves too much time and effort, regardless of consumer group (Figure 2, Table 1). Regarding the last question, those reporting 
using 0 or 1-2 bottles per week, felt more guilty after discarding a plastic bottle than the rest of the groups (Table 1).

"It is safer to drink bottled water than tap water"

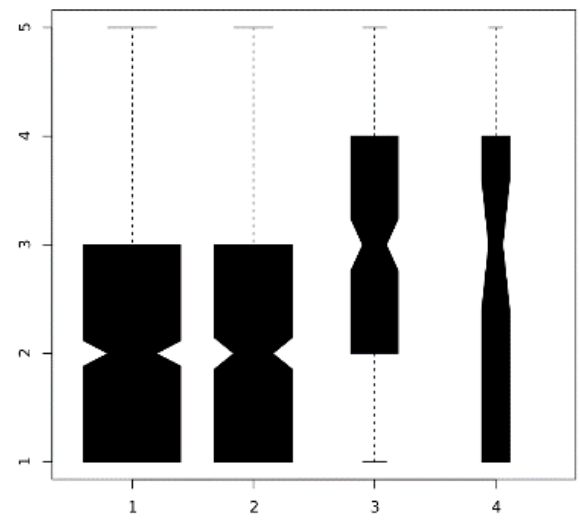

"At the university campus there are not appropriate facilities to refill the bottles"

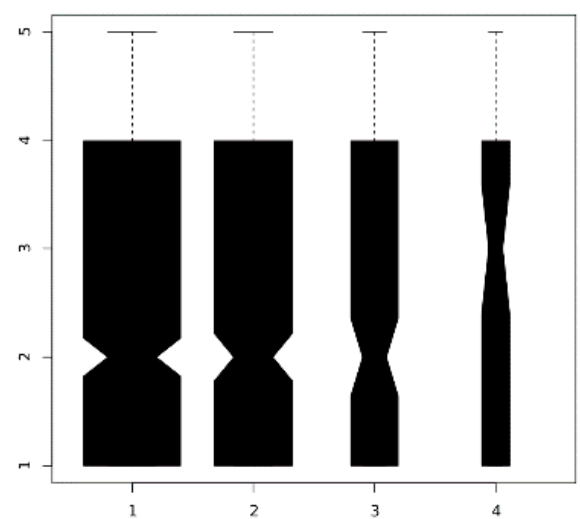

"I prefer the taste of bottled water more than that of tap water"

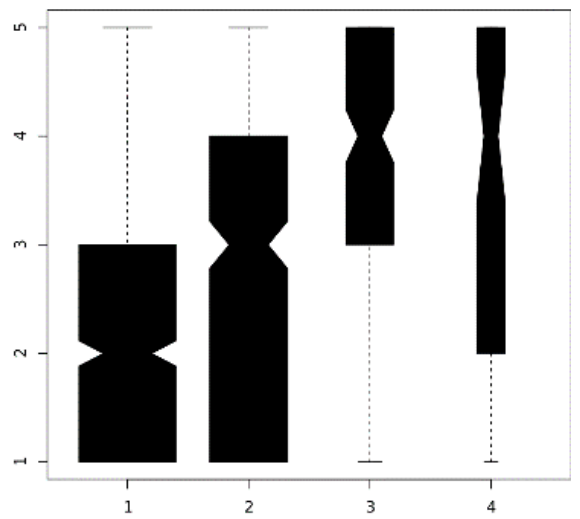

"Reusing plastic bottles involves too much time and effort"

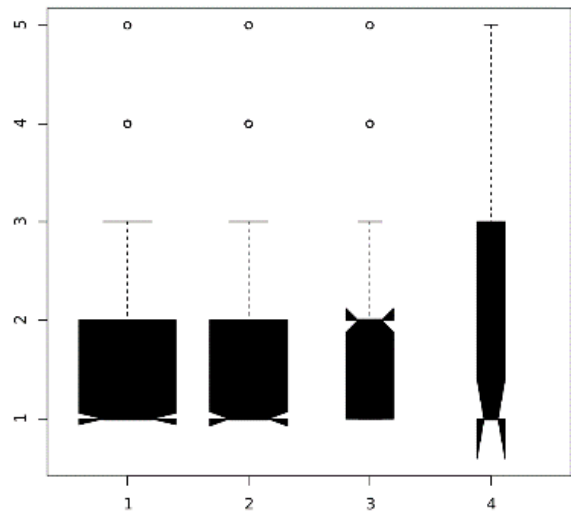

"I feel guilty if I bin a plastic bottle after a single use"

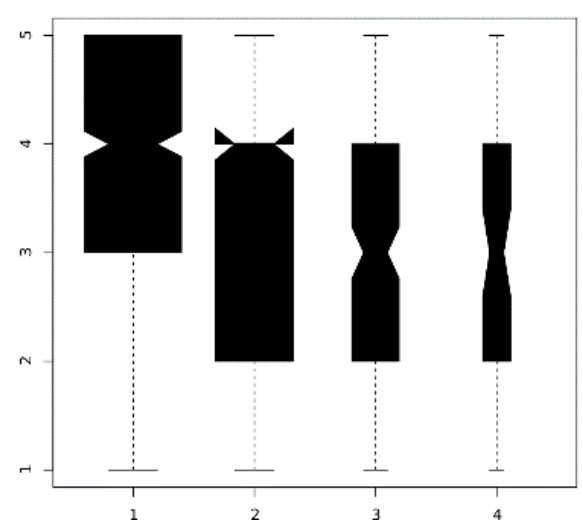

Figure 2. Perceived risks and benefits of drinking bottled water versus tap water across 4 groups of weekly bottled water consumers (x axis: 1: 0 bottle; 2: 1-2 bottles; 3: 3-5 bottles; 4: 6 or more bottles). Respondents were asked to state their agreement to the five statements shown on top of the charts following a 5-point Likert item ranging from 1: Total disagreement to 5: Total Agreement (y axis). Median values are depicted in the Box plots' notches for each bottled water consumer group. Outliers are shown as white circles. In some cases, statistical differences were observed among the groups (see Table 1). 
A second set of questions inquired about the use of reusable non-plastic water bottles. A preliminary analysis of the disaggregated data showed that nearly $72 \%$ of the respondents agreed with the statement that drinking from reusable non-plastic water bottles is safer than drinking from plastic (data not shown). This suggests that, as consumers, the respondents are aware of problems regarding the release of toxic materials, such as antimony or Bisphenol A, from polyethylene terephthalate (PET) bottles $[8,12,37]$. More than half of respondents also agreed with the inconvenience of carrying around a reusable bottle (data not shown). Nevertheless, when looking across groups of bottled water consumption, we observed that low consumers of plastic bottles found it less inconvenient carrying around non-plastic reusable bottles (Kruskal-Wallis $\mathrm{H}=29.7753, \mathrm{df}=3, p$-value $=1.539 \times 10^{-6}$; Table 2 and Supplementary File 2).

Table 1. Perceived risks and benefits of drinking bottled water versus tap water across 4 groups of bottled water consumers. Respondents were asked to state their agreement following a 5-point Likert item ranging from 1: Total disagreement to 5: Total Agreement. Mean rank values for each level of consumption are shown ${ }^{\mathrm{a}}$.

\begin{tabular}{|c|c|c|c|c|}
\hline \multirow{2}{*}{ Individual Items } & \multicolumn{4}{|c|}{ Level of Consumption per Week } \\
\hline & 1 (0 bottle); $n=729$ & $2(1-2) ; n=471$ & $3(3-5) ; \mathrm{n}=174$ & $4(\geq 6) ; n=61$ \\
\hline $\begin{array}{l}\text { "It is safer to drink bottled water than } \\
\text { tap water"* }\end{array}$ & 627.38 (a) & $773.49(b)$ & $894.01(\mathrm{c})$ & $870.48(\mathrm{bc})$ \\
\hline $\begin{array}{l}\text { "I prefer the taste of bottled water more than } \\
\text { that of tap water" * }\end{array}$ & $617.46(a)$ & $753.20(b)$ & $963.45(\mathrm{c})$ & $947.65(\mathrm{c})$ \\
\hline $\begin{array}{l}\text { "At the university campus there are not } \\
\text { appropriate facilities to refill the bottles" * }\end{array}$ & $685.67(a)$ & $724.51(\mathrm{ab})$ & 799.13 (b) & $822.61(b)$ \\
\hline $\begin{array}{l}\text { "Reusing plastic bottles involves too much } \\
\text { time and effort" * }\end{array}$ & 673.86 (a) & $743.13(a b)$ & $812.70(b)$ & $781.34(\mathrm{ab})$ \\
\hline $\begin{array}{l}\text { "I feel guilty if I bin a plastic bottle after a } \\
\text { single use" * }\end{array}$ & 774.46 (a) & $686.79(b)$ & $593.01(b)$ & $640.77(a b)$ \\
\hline \multicolumn{5}{|c|}{$\begin{array}{l}\text { a For ease of interpretation, low rank values express low levels of agreement and high rank values express high } \\
\text { levels of agreement. In those items with an asterisk, a Kruskal-Wallis rank sum test with a Bonferroni correction } \\
\text { showed statistical differences between the groups of consumption (see } p \text { values and post hoc analysis for each } \\
\text { item in Supplementary File 2). * Mean rank values with the same letter were not significantly different at the 5\% } \\
\text { confidence level based on subsequent pairwise comparisons of the mean ranks between groups [36]. }\end{array}$} \\
\hline
\end{tabular}

Table 2. Perceived risks and benefits of using reusable non-plastic water bottles across 4 groups of bottled water consumers. Respondents were asked to state their agreement following a 5-point Likert item ranging from 1: Total disagreement to 5: Total Agreement. Mean rank values for each level of consumption are shown ${ }^{\mathrm{a}}$.

\begin{tabular}{|c|c|c|c|c|}
\hline \multirow{2}{*}{ Individual Items } & \multicolumn{4}{|c|}{ Level of Consumption per Week } \\
\hline & 1 (0 bottle); $n=729$ & $2(1-2) ; n=471$ & $3(3-5) ; \mathrm{n}=174$ & $4(\geq 6) ; n=61$ \\
\hline $\begin{array}{l}\text { "Using glass or reusable bottles is safer than } \\
\text { using plastic bottles" }\end{array}$ & 738.78 & 697.23 & 718.51 & 628.56 \\
\hline $\begin{array}{l}\text { "By using a glass or reusable bottle, I } \\
\text { motivate others to do the same" }\end{array}$ & 743.13 & 699.94 & 667.87 & 700.09 \\
\hline $\begin{array}{l}\text { "Carrying around a glass or reusable bottle } \\
\text { is inconvenient" * }\end{array}$ & $666.3(a)$ & $761.91(b)$ & $759.41(b)$ & 878.68 (b) \\
\hline \multicolumn{5}{|c|}{$\begin{array}{l}\text { a For ease of interpretation, low rank values express low levels of agreement and high rank values express high } \\
\text { levels of agreement. In those items with an asterisk, a Kruskal-Wallis rank sum test with a Bonferroni correction } \\
\text { showed statistical differences between the groups of consumption (see } p \text { values and post hoc analysis for each } \\
\text { item in Supplementary File 2). * Mean rank values with the same letter were not significantly different at the 5\% } \\
\text { confidence level based on subsequent pairwise comparisons of the mean ranks between groups [36]. }\end{array}$} \\
\hline
\end{tabular}

The third set of eight questions asked the participants about the perceived benefits of drinking tap water and its environmental implications. A preliminary analysis of disaggregated data showed that, in general, there was an agreement with statements related to the quality and convenience of tap water, and about local and global environmental implications of consuming tap water, such as 
contribution to reducing personal $\mathrm{CO}_{2}$ emissions or oil consumption (data not shown). Table 3 and Figure 3 show that low consumers (Group 1 ) of bottled water agreed more strongly about the quality and convenience of drinking tap water. These results are in agreement with previous studies that have shown important differences in beliefs between high and low users of bottled water regarding the existence of real alternatives to bottled water or whether important changes in lifestyle would be required to reduce bottled water consumption [10].

Figure 3 shows results regarding a set of questions aimed to measure participants' beliefs about their own contribution to protect the environment by drinking tap water instead of bottled water and clear statistical differences were observed between low (Group 1) and high bottled water users (Group 4) (Table 3). Several authors have asserted that environmental impacts may have become peripheral rather than the central concerns when it comes to personal decisions to buy bottled water $[10,28]$. In our study, this could be the case for frequent consumers of bottled water.

Table 3. Perception of benefits and environmental implications of consuming tap water across 4 groups of bottled water consumers. Respondents were asked to state their agreement following a 5-point Likert item ranging from 1: Total disagreement to 5: Total Agreement. Mean rank values for each level of consumption are shown ${ }^{\mathrm{a}}$.

\begin{tabular}{|c|c|c|c|c|}
\hline \multirow{2}{*}{ Individual Items } & \multicolumn{4}{|c|}{ Level of Consumption per Week } \\
\hline & 1 (0 bottle); $n=729$ & $2(1-2) ; n=471$ & $3(3-5) ; n=174$ & $4(\geq 6) ; n=61$ \\
\hline "Tap water is cheaper than bottled water" & 740.88 & 718.27 & 649.77 & 637.07 \\
\hline "I trust tap water's quality" *,+ & 799.32 (a) & 695.79 (b) & $517.31(\mathrm{c})$ & $490.10(\mathrm{c})$ \\
\hline $\begin{array}{l}\text { "If I drink tap water I don't have to go to the } \\
\text { cafeteria or the machine to purchase } \\
\text { bottled water" * }\end{array}$ & 787.43 (a) & $667.27(b)$ & $599.80(b)$ & $617.19(b)$ \\
\hline $\begin{array}{l}\text { "If I drink tap water I am contributing less plastic } \\
\text { to landfills" * }\end{array}$ & 771.74 (a) & $700.14(b)$ & $593.65(c)$ & $568.34(\mathrm{bc})$ \\
\hline $\begin{array}{l}\text { "If I drink tap water I can reduce my } \\
\text { consumption of oil to make plastics" * }\end{array}$ & 770.92 (a) & 713.10 (a) & $552.72(b)$ & $594.86(\mathrm{ab})$ \\
\hline $\begin{array}{l}\text { "If I drink tap water, I am reducing my personal } \\
\text { contribution to global climate change" * }\end{array}$ & 763.61 (a) & $704.86(a b)$ & $604.38(\mathrm{c})$ & $598.45(\mathrm{bc})$ \\
\hline $\begin{array}{l}\text { "If I drink tap water, I am helping to make our } \\
\text { campus more sustainable" * }\end{array}$ & 766.49 (a) & $702.12(\mathrm{abc})$ & $612.11(\mathrm{bc})$ & $563.20(\mathrm{c})$ \\
\hline $\begin{array}{l}\text { "When I go to the campus restaurant, I can get } \\
\text { tap water" }\end{array}$ & 736.03 & 708.52 & 679.26 & 686.22 \\
\hline \multicolumn{5}{|c|}{$\begin{array}{l}\text { a For ease of interpretation, low rank values express low levels of agreement and high rank values express high } \\
\text { levels of agreement. In those items with an asterisk, a Kruskal-Wallis rank sum test with a Bonferroni correction } \\
\text { showed statistical differences between the groups of consumption (see } p \text { values and post hoc analysis for each } \\
\text { item in Supplementary File } 2 \text { ). }{ }^{*} \text { Mean rank values with the same letter were not significantly different at the } 5 \% \\
\text { confidence level based on subsequent pairwise comparisons of the mean ranks between groups [36]. }{ }^{+} \text {This item } \\
\text { was recoded. }\end{array}$} \\
\hline
\end{tabular}

\subsection{Environmental Policies at the Center/Faculty Level Regarding Bottled and Tap Water Use}

Through on-line surveys and a few telephonic interviews, data about tap water accessibility and plastic bottled water use was obtained from 29 out of the 31 faculties at the university. In research centers and administrative premises, 13 out of 16 administrators responded the on-line survey. Table 4 shows the frequency of responses to the 7 questions and their analysis gives a snapshot of the current status of bottled water and tap water accessibility at our university. The overwhelming majority of assessed centers have vending machines that sell plastic water bottles (95\%, Table 4), and while most of them also have free-dining areas $(86 \%)$, only a third of them have accessibility to tap water within those areas. The limited accessibility is also highlighted by the fact that only $24 \%$ of the examined centers have drinking fountains. Despite this, $48 \%$ of the interviewed deans or administrators stated that they provide glass jugs in academic ceremonies. Moreover, when asked whether they had carried out measures or initiatives to promote the use of tap water in their premises, $48 \%$ responded affirmatively. These initiatives at the center/faculty level include the distribution of glass jugs to use in talks and events, the installation of 
sinks in free-dining areas, the installation of water fountains, the organization of tap water awareness campaigns, or the distribution to staff members of corporative glass bottles for tap water use.
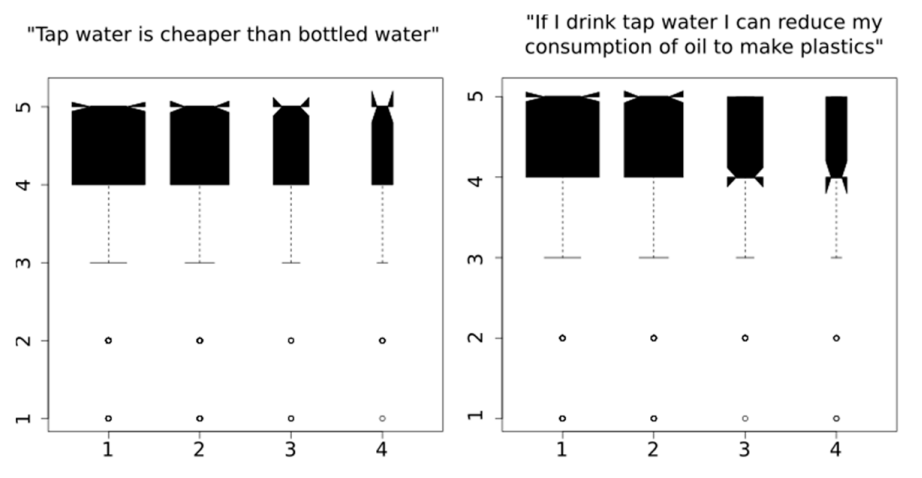

"I trust tap water's quality"

"If I drink tap water, I am reducing my personal contribution to global climate change"
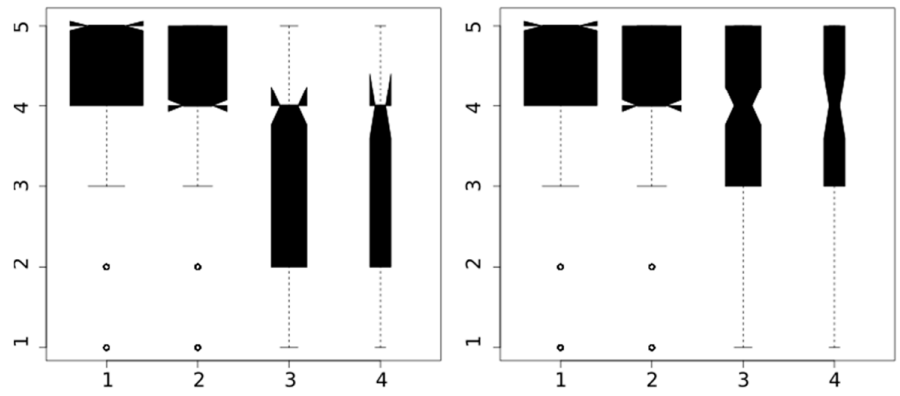

"If I drink tap water I don't have to go to the cafeteria or the machine to purchase bottled water"

"If I drink tap water, I am helping to make our campus more sustainable"
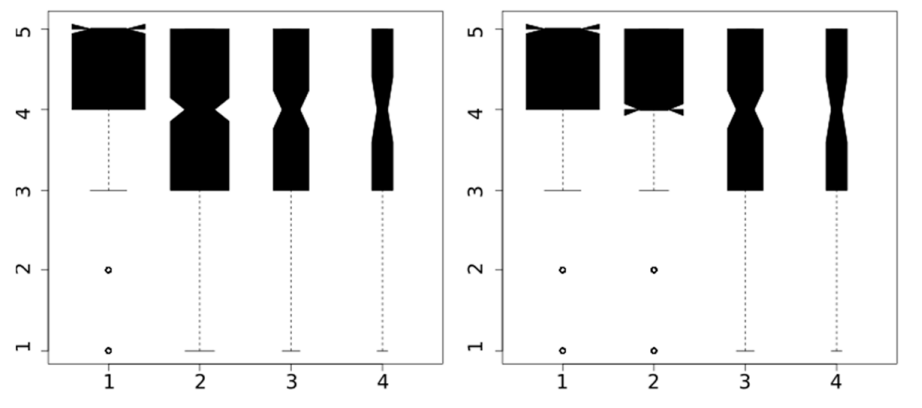
contributing less plastic to landfills"

"When I go to the campus

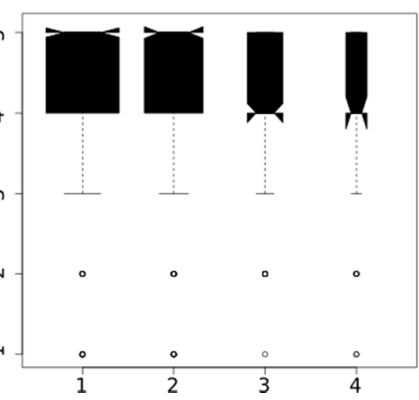
restaurant, I can get tap water"

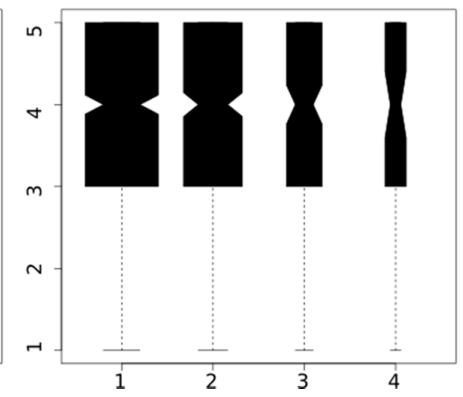

Figure 3. Perception of benefits and environmental implications of consuming tap water across 4 groups of weekly bottled water consumers (x axis: 1: 0 bottle; 2: 1-2 bottles; 3: 3-5 bottles; 4 : 6 or more bottles). Respondents were asked to state their agreement to the eight statements shown on top of the charts following a 5-point Likert item ranging from 1: Total disagreement to 5: Total Agreement (y axis). Box plots depicting median values for each bottled water consumer group are shown. Outliers are shown as white circles. In some cases, statistical differences were observed among the groups (see Table 3). 
Table 4. Frequency of responses of university schools' deans and research centers' and administration buildings' administrators regarding the availability of tap water and the use of plastic water bottles in their premises ( $\mathrm{n}=41$ schools/centers/buildings).

\begin{tabular}{lcc}
\hline & YES (\%) & NO (\%) \\
\hline $\begin{array}{l}\text { 1. During academic ceremonies (PhD vivas, meetings) in your } \\
\text { school/center/building, do you provide tap water in glass jugs? }\end{array}$ & 48 & 52 \\
\hline $\begin{array}{l}\text { 2. Do you have non-commercial dining areas in your } \\
\text { school/center/building? }\end{array}$ & 86 & 14 \\
\hline 3. If you answered yes, are there tap water facilities? & 67 & 33 \\
\hline $\begin{array}{l}\text { 4. Are there tap water fountains in your school/center/building? } \\
\text { 5. Are there vending machines selling plastic bottled water in your } \\
\text { school/center/building? }\end{array}$ & 24 & 76 \\
\hline $\begin{array}{l}\text { 6. Are there cold water dispensers in your school/center/building? } \\
\text { 7. Have you taken any action to reduce the use of plastic water bottles } \\
\text { in your school/center/building? }\end{array}$ & 48 & 52 \\
\hline
\end{tabular}

\subsection{Bottled Water Sales Volume in University Canteens and Restaurants}

Out of the 23 restaurants contacted by telephone, 18 conducted the interview satisfactorily, providing data regarding sales volumes for $78 \%$ of the university canteens and restaurants. In all of these premises, bottled water is sold and the sales volume varies around 2 to 10 bottles up to 40 bottles per week. The most common bottle sizes are 20, 35, or $50 \mathrm{cL}$, with the $35 \mathrm{cL}$ bottle being the top seller. In the restaurants, $1.5 \mathrm{~L}$ bottles are also incorporated in the lunch menus, especially on those premises that do not offer water jugs. In all restaurants, vending machines are available within the premises, which include bottled water. Data from the biggest cafeteria in the Leioa campus obtained during three weeks in September 2013 provides a snapshot of the context: 5280 bottles of 0.35 cL, 96 bottles of $0.5 \mathrm{cL}$, and 48 bottles of $1.5 \mathrm{~L}$. The sales volume of small plastic bottles is striking. This data also help us to have a more realistic view of the bottled water use at the university, since it helps to focus the direction of the efforts that could be made to reduce bottled water use. The data also contrasts with survey respondents attitudes, since half of them stated that they do not drink bottled water.

Restaurant managers were also asked their reasoning behind choosing particular brands of water, and taste was the most prevalent. In other cases, managers sold filtered tap water brands distributed by big soft drinks corporations. Finally, in some cases, the restaurant manager would attempt to meet customer demand and offer low mineralization waters or popular brands. Restaurant managers were also asked about waste management and all of them stated that they recycled the plastic, despite the efforts it required in some cases. Regarding the use of glass jugs to provide tap water in lunch menus, it is noteworthy to highlight that the Gipuzkoa campus is the only campus where all the restaurants offer glass jugs by default. This has not eliminated the sale of bottled water but has reduced it considerably compared to the other campuses. Another interesting example is the Leioa cafeteria, the biggest in the university and situated in the Leioa campus $(125,000$ self-service lunch meals sold per year), which since 2012 does not provide bottled water in the self-service canteen. Along with this measure, glass jugs and tap water are available free of charge. Both measures reduced the presence of bottled water in fixed lunch menus to only $6 \%$ of the sold menus. Regarding the Araba campus, the smallest, the situation is different and only in the fast self-service menu is the use of glass jugs possible, whereas in the remaining restaurants, bottled water is served by default in the fixed menus.

\section{Discussion}

The exploratory survey results show that respondents predominately drink tap water and health risks or taste issues associated with its consumption are not perceived, and that these perceptions are mostly among those that buy few bottles per week. These results contrast with the results obtained 
at Princeton University [24], and some Asian universities [25], and could be partly explained by the high quality and regulation of drinking water in Spain. The survey analysis also showed that there is a considerable awareness of the potential environmental and health impact due to bottled water consumption: a good proportion of the respondents did not purchase more than three bottles per week and if they did so, they felt guilty about it and were aware of the environmental implications of buying or reusing plastic bottles. Moreover, low users of bottled water did not think it was too inconvenient to carry a non-plastic refillable bottle with them. However, in most cases, the container used to carry tap water was a reused plastic bottle. Although it has been shown that, with bottle aging, the release of antimony to the contained tap water does not increase [38], reusing single-use plastic bottles does not compensate for the energy costs undertaken in bottle production, whereas shifting to use a durable bottle for water consumption is economically and environmentally a better option [24].

The overall sales volume of bottled water at UPV/EHU suggests that consumption of bottled water and the perception of bottled water as a convenient good [22] is far greater than expected, and, as our survey showed, not determined by health or taste issues in local tap water. Therefore, we do not think that management efforts should be made solely towards public awareness campaigns [39]. As pointed by van der Linden [10], persuasive information alerting to the environmental issues associated with bottled water use and the accompanying benefits of drinking tap water, coupled with social norm behavioral change strategies that identify the incongruence between one's personal attitudes and real personal actions towards the environment would appear to target this issue in a more effective way. Using the theory of planned behavior, Qian [25], also showed that certain behavioral change can be induced by the design of policies that enact personal norms favoring behaviors that care more for the environment and engage more with the community. Such education and marketing campaigns should be aimed mainly at university students. Because it is the biggest collective, it has the power to influence its peers and future generations to produce social transformation [40], and in our survey, it was the collective that reported drinking the most bottled water.

Along with such behavioral change campaigns and given that both availability of tap water and measures taken towards promoting tap water consumption vary from campus to campus and within different faculties in each campus, a good starting point would be to take financial decisions that allow the installation of tap water fountains in all faculties and research buildings at UPV/EHU. A recent case study showed that an information campaign about the possibility to introduce water bottle refill stations (WRS) as a means to encourage pro-environmental behavior among students increased the willingness to use WRS [41], thereby avoiding the use of disposable plastic bottles and reducing related $\mathrm{CO}_{2}$ emissions. A second managerial decision could be the agreement with catering providers that tap water is served by default in fixed menus at university restaurants. Other accompanying measures could be the restriction of sales of bottled water in vending machines.

In the longer term, the authors of this paper consider that a total ban of single-use plastic water bottles in vending machines and restaurants should be implemented, as it has been done in other academic settings [39]. However, ban policies tend to attract criticism by the bottled water industry and there is some academic controversy about whether ban policies could shift the consumption towards other less healthy bottled beverages and limit the reduction of plastic entering the waste stream at the university campus $[28,42,43]$. Public institutions face a big challenge, because industry is able to shift its marketing strategies and, despite increasing opposition, plastic bottles are still perceived by many as a convenient good. In light of this, we adhere to the reflections by Hawkins [28], who stresses that where water infrastructure and governance are reasonable, such as in our context, it is paramount to promote "the value of a publicly owned collective water supply and universal access as a fundamental element of civic sociality ... and actively brand and market tap water as a valuable and unique product". Whether a plan that includes a total ban or progressive reduction of single-use plastic water bottles were to be carried out at UPV/EHU, further research investigating its impact on university members' attitudes and choices towards water consumption should be carried out. 


\section{Conclusions and Limitations of the Study}

The results and implications derived from this research explore the evidence of the role that personal norms and behaviors have regarding tap and bottled water consumption $[10,24,25,41]$ and help to define adequate management policies in our context and beyond. The research presented here was completed in 2014 and is largely based on data obtained in 2013. Although, our university has continued to advance its environmental sustainability [6], this study still provides a useful baseline to inform adequate policies. In this sense, the implications must be locally considered mainly because the quality and price of tap water in our context does not pose an objective obstacle towards its consumption $[14,26]$.

Perceptions and environmental attitudes towards tap water were analyzed through respondent's self reports, which is a limitation in this type of study, as noted by Uehara and Ynacay-Nye [41], mainly because the gap between attitude and environmental behavior cannot be ignored, especially if we ask university members to make radical changes.

Another aspect that could not be addressed in this study is the relationship between campus-based tap water availability and respondent's self-reporting of bottled water consumption, beliefs, and environmental attitudes. Further research should aim to identify on a campus-based scale whether particular policies implemented to increase access to tap water and reduce bottled water consumption have an effect on these perceptions. This way, we could address the question of whether campus governance represents an opportunity or a barrier for sustainability, as posed by Colding and Barthel [31]. In fact, these authors argue that considering the campus area as a local community strengthens the function of local authorities in reaching sustainable goals. Such policies should be aligned with actions defined in the Sustainable Development Goals [44], which have been endorsed by our university in its Strategic Plan [6]. As Sterling pointed out [30], Higher Education institutions face the challenge to become transformative in ways and on terms that may be still uncertain, and we hope that this and further research empowers UPV/EHU to take informed decisions towards a more sustainable future.

Supplementary Materials: The following are available online at http:/ /www.mdpi.com/2071-1050/10/10/ 3431/s1, Supplementary File 1: Survey in Basque and Spanish; Supplementary File 2: R statistical output of Kruskal-Wallis rank sum test with a Bonferroni correction for differences between groups of bottled water consumption for items in Tables 1-3.

Author Contributions: Conceptualization, J.R., A.R. and I.A.; Methodology, J.R. and A.R.; Validation, A.R. Formal Analysis, J.R., E.A., A.R.; Data Curation, A.R.; Writing-Original Draft Preparation, J.R. and A.R.; Writing-Review \& Editing, J.R., I.A., E.A. and A.R.

Funding: This research was funded by Vicerectorate of Students, Employment and Social Responsibility (UPV/EHU; grant for Sustainability Innovation).

Acknowledgments: We wish to thank all the students, lecturer, researchers and administrative staff that filled in the survey and specially to all our colleagues that helped us to disseminate it. We thank R. Agerri and C. Daher for critically reading the manuscript and for helpful suggestions.

Conflicts of Interest: The authors declare no conflict of interest. The funders had no role in the design of the study; in the collection, analyses, or interpretation of data; in the writing of the manuscript, and in the decision to publish the results.

\section{References}

1. Cullingford, C.; Blewitt, J. The Sustainability Curriculum: The Challenge for Higher Education; Routledge: Abingdon, UK, 2013; ISBN 978-1-136-55209-0.

2. Mcmillin, J.; Dyball, R. Developing a Whole-of-University Approach to Educating for Sustainability: Linking Curriculum, Research and Sustainable Campus Operations. J. Educ. Sustain. Dev. 2009, 3, 55-64. [CrossRef]

3. Alshuwaikhat, H.M.; Abubakar, I. An integrated approach to achieving campus sustainability: Assessment of the current campus environmental management practices. J. Clean. Prod. 2008, 16, 1777-1785. [CrossRef]

4. Dumitrascu, O.; Ciudin, R.; Dumitrascu, O.; Ciudin, R. Modeling Factors with Influence on Sustainable University Management. Sustainability 2015, 7, 1483-1502. [CrossRef] 
5. Decreto $17 / 2011$, de 15 de febrero, por el que se aprueban los estatutos de la Universidad del País Vasco/Euskal Herriko Unibertsitatea. Boletín Oficial País Vasco 2011, 38, 1-89. Available online: https: / / www.ehu.eus/documents /2007376/3869011/Estatutos_EHU.pdf/c15f4b39-6706-49a0-b0f22786d358fa29 (accessed on 25 September 2018).

6. Universidad del País Vasco/Euskal Herriko Unibertsitatea. Plan Estratégico 2018/2021, Servicio Editorial de la Universidad del País Vasco. 2018, pp. 5-31. Available online: https:/ / www.ehu.eus/documents/1769324/ 0/Plan+estrategico+cas+18-21/46a4a9e6-ad8a-8cb9-c701-2269fdd2179f (accessed on 25 September 2018).

7. European Federation of Bottled Waters Natural Mineral \& Spring Waters. Brusels, Belgium. Industry Report 2016. 2016. Available online: https://www.efbw.org/fileadmin/user_upload/documents/Publications/EFBW_ Industry_Report_interactive_web_PDF_version_final.pdf (accessed on 25 September 2018).

8. Gleick, P.H.; Cooley, H.S. Energy implications of bottled water. Environ. Res. Lett. 2009, 4. [CrossRef]

9. Parag, Y.; Roberts, J.T. A Battle against the Bottles: Building, Claiming, and Regaining Tap-Water Trustworthiness. Soc. Nat. Resour. 2009, 22, 625-636. [CrossRef]

10. Van der Linden, S. Exploring Beliefs about Bottled Water and Intentions to Reduce Consumption: The Dual-Effect of Social Norm Activation and Persuasive Information. Environ. Behav. 2015, 47, 526-550. [CrossRef]

11. Brede, C.; Fjeldal, P.; Skjevrak, I.; Herikstad, H. Increased migration levels of bisphenol A from polycarbonate baby bottles after dishwashing, boiling and brushing. Food Addit. Contam. 2003, 20, 684-689. [CrossRef] [PubMed]

12. Shotyk, W.; Krachler, M.; Chen, B. Contamination of Canadian and European bottled waters with antimony from PET containers. J. Environ. Monit. 2006, 8, 288-292. [CrossRef] [PubMed]

13. European Commission Proposal for a Directive of the European Parliament and of the Council on the Quality of Water Intended for Human Consumption (Recast). COM/2017/0753 Final-2017/0332 (COD). 2017. Available online: https:/ / eur-lex.europa.eu/legal-content/en/TXT/?uri=CELEX:52017PC0753 (accessed on 25 September 2018).

14. Council Directive 98/83/EC of 3 November 1998 on the Quality of Water Intended for Human Consumption. Available online: https:/ / eur-lex.europa.eu/legal-content/EN/TXT/?uri=CELEX\%3A31998L0083 (accessed on 25 September 2018).

15. Malkin, B. Australian town bans bottled water. The Telegraph, 8 July 2009.

16. Levin, S. How San Francisco is leading the way out of bottled water culture. The Guardian, 28 June 2017.

17. $\mathrm{Ng}$, Y. Hong Kong dumps $5.2 \mathrm{~m}$ bottles a day-Is it time for a plastic ban? South China Morning Post, 20 October 2017.

18. CBC News Plastic Water Bottles to Be Banned from Montreal City Buildings Following Unanimous Vote I CBC News. Available online: https:/ /www.cbc.ca/news/canada/montreal/plastic-water-bottles-to-be-bannedfrom-montreal-city-buildings-following-unanimous-vote-1.4683568 (accessed on 16 September 2018).

19. Ban the Bottle I a Blog Devoted to Banning Plastic Water Bottles \& Staying Hydrated. Available online: https:/ / www.banthebottle.net/ (accessed on 25 September 2018).

20. Nunes, B.; Pollard, S.; Burgess, P.; Ellis, G.; de los Rios, I.; Charnley, F.; Nunes, B.T.; Pollard, S.J.T.; Burgess, P.J.; Ellis, G.; et al. University Contributions to the Circular Economy: Professing the Hidden Curriculum. Sustainability 2018, 10, 2719. [CrossRef]

21. European Commission. Proposal for a Directive of the European Parliament and of the Council on the Reduction of the Impact of Certain Plastic Products on the Environment. COM/2018/340 Final-2018/0172 (COD). 2018. Available online: https:/ / eur-lex.europa.eu/legal-content/en/TXT/?uri=CELEX:52018PC0340 (accessed on 26 September 2018).

22. Doria, M. Bottled water versus tap water: Understanding consumers-preferences. J. Water Health 2006, 4, 271-276. [CrossRef] [PubMed]

23. Hu, Z.; Morton, L.W.; Mahler, R. Bottled Water: United States Consumers and Their Perceptions of Water Quality. Int. J. Environ. Res. Public Health 2011, 8, 565-578. [CrossRef] [PubMed]

24. Saylor, A.; Prokopy, L.S.; Amberg, S. What's Wrong with the Tap? Examining Perceptions of Tap Water and Bottled Water at Purdue University. Environ. Manag. 2011, 48, 588-601. [CrossRef] [PubMed]

25. Qian, N. Bottled Water or Tap Water? A Comparative Study of Drinking Water Choices on University Campuses. Water 2018, 10, 59. [CrossRef] 
26. European Union, P.O. of the E. Water: What's in It for You? Available online: https://publications. europa.eu/en/publication-detail/-/publication/6ea03452-1803-11e6-ba9a-01aa75ed71a1 (accessed on 16 September 2018).

27. Wilk, R. Bottled Water: The pure commodity in the age of branding. J. Consum. Cult. 2006, 6, 303-325. [CrossRef]

28. Hawkins, G. Packaging water: Plastic bottles as market and public devices. Econ. Soc. 2011, 40, 534-552. [CrossRef]

29. Queiroz, J.T.M. News about Tap and Bottled Water: Can This Influence People's Choices? J. Environ. Prot. 2012, 3, 324-333. [CrossRef]

30. Sterling, S. Higher Education, Sustainability, and the Role of Systemic Learning. In Higher Education and the Challenge of Sustainability; Springer: Dordrecht, The Netherlands, 2004; pp. 49-70. ISBN 978-1-4020-2026-1.

31. Colding, J.; Barthel, S.; Colding, J.; Barthel, S. The Role of University Campuses in Reconnecting Humans to the Biosphere. Sustainability 2017, 9, 2349. [CrossRef]

32. Sedlacek, S. The role of universities in fostering sustainable development at the regional level. J. Clean. Prod. 2013, 48, 74-84. [CrossRef]

33. Fox, J. The R Commander: A Basic Statistics Graphical User Interface to R. J. Stat. Softw. 2005, 14, 1-42. [CrossRef]

34. Kruskal, W.H.; Wallis, W.A. Use of Ranks in One-Criterion Variance Analysis. J. Am. Stat. Assoc. 1952, 47, 583-621. [CrossRef]

35. Jamieson, S. Likert scales: How to (ab)use them. Med. Educ. 2004, 38, 1217-1218. [CrossRef] [PubMed]

36. Siegel, S.; Castellan, J. Non parametric Statistics for the Behavioural Sciences; McGraw-Hill Int.: New York, NY, USA, 1988.

37. Wagner, M.; Oehlmann, J. Endocrine disruptors in bottled mineral water: Estrogenic activity in the E-Screen. J. Steroid Biochem. Mol. Biol. 2011, 127, 128-135. [CrossRef] [PubMed]

38. Tukur, A.; Sharp, L.; Stern, B.; Tizaoui, C.; Benkreira, H. PET bottle use patterns and antimony migration into bottled water and soft drinks: The case of British and Nigerian bottles. J. Environ. Monit. 2012, 14, 1236-1246. [CrossRef] [PubMed]

39. D'Altrui, E.M. Bottle Water Bans: How can we curb the thirst for bottled water? Elements 2017, 13, 53-63. [CrossRef]

40. Di Fabio, A.; Kenny, M.; Di Fabio, A.; Kenny, M.E. Academic Relational Civility as a Key Resource for Sustaining Well-Being. Sustainability 2018, 10, 1914. [CrossRef]

41. Uehara, T.; Ynacay-Nye, A.; Uehara, T.; Ynacay-Nye, A. How Water Bottle Refill Stations Contribute to Campus Sustainability: A Case Study in Japan. Sustainability 2018, 10, 3074. [CrossRef]

42. Berman, E.R.; Johnson, R.K. The Unintended Consequences of Changes in Beverage Options and the Removal of Bottled Water on a University Campus. Am. J. Public Health 2015, 105, 1404-1408. [CrossRef] [PubMed]

43. Bohme, S.R.; Berman, E.R.; Johnson, R.K. Beverage policy article too limited to show consequences/Berman and Johnson respond. Am. J. Public Health 2016, 106, 9. [CrossRef] [PubMed]

44. General Assembly Resolution 70/1. Transforming our World: The 2030 Agenda for Sustainable Development. A/RES/70/1. 2015. Available online: http://www.un.org/ga/search/view_doc.asp?symbol=A/RES/70/ $1 \&$ Lang $=\mathrm{E}$ (accessed on 25 September 2018).

(C) 2018 by the authors. Licensee MDPI, Basel, Switzerland. This article is an open access article distributed under the terms and conditions of the Creative Commons Attribution (CC BY) license (http://creativecommons.org/licenses/by/4.0/). 